\title{
Tail bifurcation in two species of Desmognathus salamander (Caudata: Plethodontidae) in south-eastern Kentucky, USA
}

\author{
J. ALEX BAECHER*, EMILY JONES \& STEPHEN C. RICHTER \\ Department of Biological Sciences and Division of Natural Areas, Eastern Kentucky University, \\ Richmond, Kentucky 40475, USA \\ *Corresponding author e-mail: jbaecher@gmail.com
}

\begin{abstract}
Eor centuries, amphibian malformations have been - documented globally and in veritable detail (Vallisneri, 1706; Bourne, 1884; Ouellet, 2000; Haas et al., 2018), particularly in anurans (Lannoo, 2008). Although, rarely have malformations been documented in caudates (for a review of the literature, see Henle et al., 2012), primarily manifesting as post-larval tail malformations (i.e. bifurcation and duplication). Furthermore, among the caudate families in which malformations have been reported, the Plethodontidae - the largest caudate family - has been apparently underrepresented, with only three of the $>470$ species documented to exhibit malformations (Henle et al., 2012; Hartzell, 2017). Previously, tail bifurcation within the genus Desmognathus (Caudata: Plethodontidae) has only been reported in D. fuscus (Rafinesque, 1820) (Hartzell, 2017). We report here tail bifurcation in natural populations of D. ochrophaeus Cope 1859 and D. monticola Dunn 1916. To our knowledge, these observations represent the first reports of tail bifurcation in either species.
\end{abstract}

On 7 June 2017, a post-larval D. ochrophaeus exhibiting tail bifurcation (Fig. 1a) was observed in a headwater stream that originates and flows through an old-growth forest. The bifurcation occurred at approximately $1 / 4$ length of the tail from the cloaca. On 19 May 2018, an additional post-larval tail bifurcation was observed in $D$. monticola (Fig. 1b). This bifurcation appeared similar to the malformation previously observed in $D$. ochrophaeus, occurring at approximately $1 / 4$ to $1 / 3$ length of the tail from the cloaca. Both salamanders were hand-captured in the riparian area of a small, forested headwater stream $\left(37.078398^{\circ} \mathrm{N},-82.994013^{\circ} \mathrm{W}\right.$, WGS 84, 355 m elev.) at Lilley Cornett Woods Appalachian Ecological Research Station (Letcher Co., Kentucky, U.S.A.).

\section{ACKNOWLEDGEMENTS}

This is contribution No. 54 of Lilley Cornett Woods Appalachian Ecological Research Station, Eastern Kentucky University (EKU). Amphibian handling protocols were approved by the EKU Animal Care and Use Committee (\#052015). Funding was provided by EKU Division of Natural Areas and National Science Foundation Research Experience for Undergraduates (NSF REU) program, Disturbance Ecology in Central Appalachia (DBI-1559980). We thank J. Folkerts and participants of the NSF REU, S. Ashbrook, P. Blair, H. Conner, P. Grap, K. Hoefer, J. James, R. Miller, J. Peters, J. Portman,
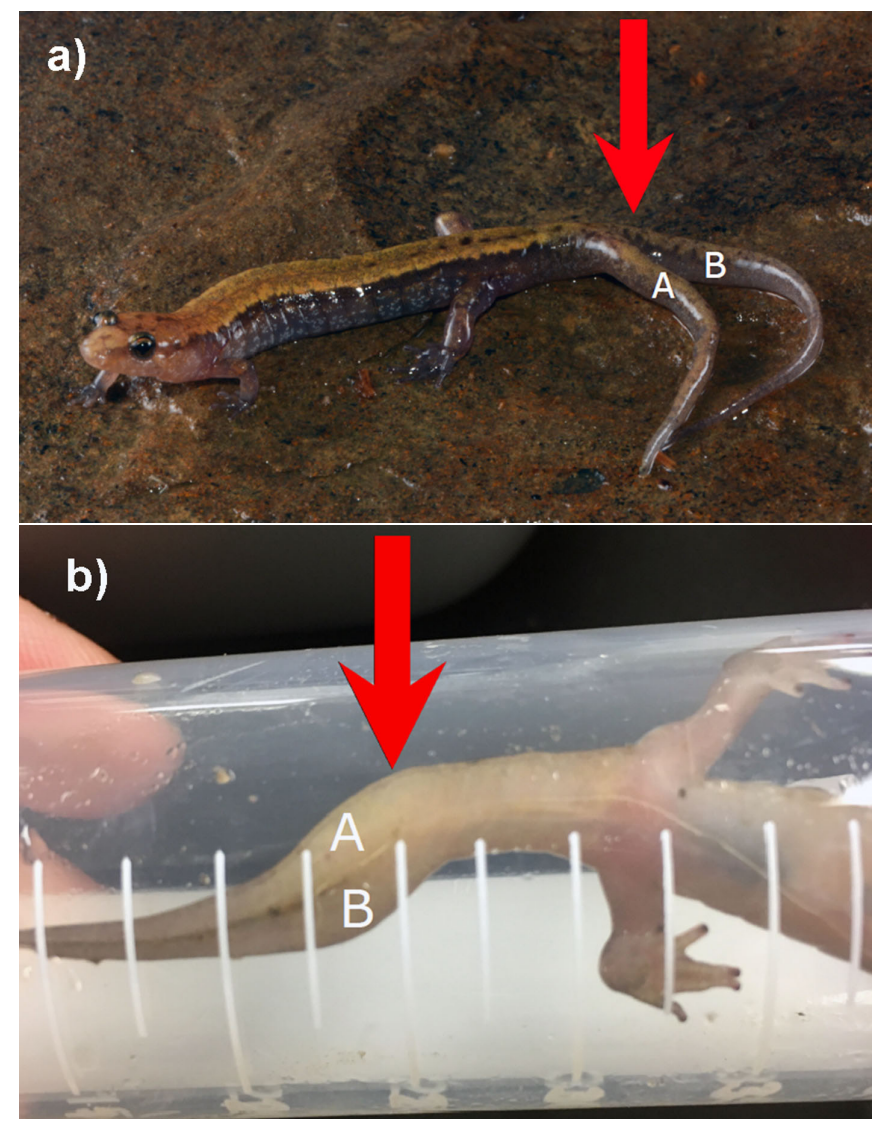

Figure 1. Tail bifurcation in two species of salamander captured in a headwater stream at Lilley Cornett Woods Appalachian Ecological Research Station in Letcher County, Kentucky, U.S.A. a) Dorsal view of the tail of an adult $D$. ochrophaeus, and $\mathbf{b}$ ) ventral view of the tail of an adult $D$. monticola to show tail bifurcation. Red arrows indicate the point of bifurcation. Beyond point of bifurcation, individual tail segments are labelled ' $A$ ' and ' $B$ '.

J. Stalker, for their curiosity and dedication to the study of Appalachian natural history.

\section{REFERENCES}

Bourne, A.G. (1884). On certain abnormalities in the common frog (Rana temporaria). Quarterly Journal of Microscopical Science 2: 83-88.

Haas, S.E., Reeves, M.K., Pinkney, A.E. \& Johnson, P.T.J. (2018). Continental-extent patterns in amphibian malformations linked to parasites, chemical contaminants, and their 
interactions. Global Change Biology 24: e275-e288.

Hartzell, S.M. (2017). Tail bifurcation in a Northern dusky salamander, Desmognathus fuscus (Caudata: Plethodontidae). Herpetology Notes 10: 181-182.

Henle, K., Mester, B., Lengyel, S. \& Puky, M. (2012). A review of a rare type of anomaly in amphibians, tail duplication and bifurcation, with description of three new cases in Europeanspecies(Triturusdobrogicus, Trituruscarnifex, and Hyla arborea). Journal of Herpetology 46: 451-455.

Lannoo, M. (2008). Malformed Frogs: the Collapse of Aquatic Ecosystems. University of California Press, West Sussex, U.K.
Ouellet, M. (2000). Amphibian deformities: Current state of knowledge. In Ecotoxicology of Amphibians and Reptiles, pp. 617-646. Sparling, D., Linder, G. \& Bishop, C. (Eds.). Pesacola, FL: SETAC Press.

Vallisneri, V.L. (1706). Galleria di Minerva Overo Notizie Universali di Quanto e Stato Scritto da Letterati di Europa. Volume 3. Venice.

Accepted: 28 August 2019 